\title{
OPEN Experimental and computational evaluation of cyclic solvent injection in fractured tight hydrocarbon reservoirs
}

\author{
Amin Ghanizadeh ${ }^{\bowtie}$, Chengyao Song, Hamidreza Hamdi \& Christopher R. Clarkson
}

Multi-fractured horizontal wells have enabled commercial production from low-permeability ('tight') hydrocarbon reservoirs but recoveries remain exceedingly small (<5-10\%). As a result, operators have investigated the use of solvent (gas) injection schemes, such as huff-n-puff (HNP), to improve oil recovery. Previous HNP laboratory approaches, classified primary as 'flow-through-matrix' and 'flowaround-matrix' typically (1) are not fully representative of field conditions at near-fracture regions and (2) require long test times, even when performed on fractured cores. The objectives of this proof-ofconcept study are to (1) design and implement a new experimental procedure that better reproduces HNP schemes in near-fracture regions and (2) use the results, simulated with a compositional labcalibrated model, to explore the controls on enhanced hydrocarbon recovery in depleted tight oil plays. Performing multiple $\mathrm{CO}_{2}$ and (simplified) lean gas $\mathrm{HNP}$ cycles, the integrated experimental and simulation approach proposed herein achieves the ultimate recovery factors in a significantly shorter time frame (25-50\%) compared to previous studies. The integrated experimental and computational approach proposed herein is valuable for core-based evaluation of cyclic solvent $\left(\mathrm{CO}_{2}\right.$, $\left.\mathrm{CH}_{4}\right)$ injection in tight hydrocarbon reservoirs for (1) hydrocarbon recovery and (2) subsurface greenhouse $\left(\mathrm{CO}_{21} \mathrm{CH}_{4}\right)$ gas disposal/storage applications.

Hydrocarbon liquid-rich shale plays are currently the hottest unconventional reservoir targets in North America. However, the majority of development has focused on primary depletion with multi-fractured horizontal wells, and hydrocarbon liquid recovery is projected to be low $(<5-10 \%)$. Further, the current recovery process is inefficient in the majority of tight oil plays, and does not offer a solution to reducing greenhouse gas emissions. A potential solution is to inject $\mathrm{CO}_{2}$, or reinject produced (lean/rich) gas recovered from the reservoir, or a combination of both, back into multi-fractured horizontal wells for the purpose of simultaneously increasing liquid hydrocarbon recovery (condensate or oil), and reducing greenhouse gas $\left(\mathrm{CO}_{2}, \mathrm{CH}_{4}\right)$ emissions. The cyclic solvent injection process, commonly referred to as huff-n-puff (HNP), with $\mathrm{CO}_{2}$ and/or lean gas as the 'solvent', is a potentially attractive mechanism for co-optimization of greenhouse gas sequestration and enhanced oil recovery (EOR) because, unlike solvent (e.g. $\mathrm{CO}_{2}$ ) flooding and water-alternating-gas flooding (e.g. $\mathrm{CO}_{2}$-WAG) (dedicated injection and producing wells) scenarios, large expenditures on specialized facilities, in-field pipelines and well conversions are unnecessary. Despite these advantages, industry requires critical data, evaluation methods, and supporting simulation studies in order to make a decision on whether to invest capital in piloting the HNP process in their operated wells/fields.

A summary of the theory behind the HNP process in tight hydrocarbon systems is provided in Supplementary Appendix S1 online. There are now numerous studies of improved oil recovery in a variety of North American tight oil reservoirs that have examined the feasibility of incremental oil recovery using gas injection ${ }^{1-6}$. These studies have primarily focused on numerical ${ }^{2,3,6}$ or laboratory-based approaches ${ }^{1,7-9}$. Laboratory-based studies are important for assessing (1) the key mechanisms controlling injected gas transport into the reservoir, and miscibility with the oil ${ }^{7,8,10}$ and (2) the influence of operational parameters including injection pressure/time, soaking time, production pressure/time-among other factors (e.g. PVT)—on recovery performance ${ }^{7,11}$. Further, laboratory-based analyses are required to (1) understand the underlying physics and (2) constrain simulation models used for HNP schemes. By matching the laboratory results (e.g. recovery factors, oil/gas production) using rigorous fine-scale numerical simulation models, critical parameters that can be used in evaluating fieldscale EOR pilots may be obtained. 
(a)

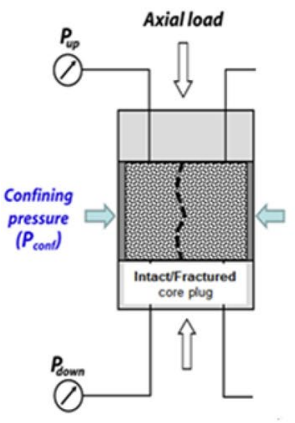

(b)

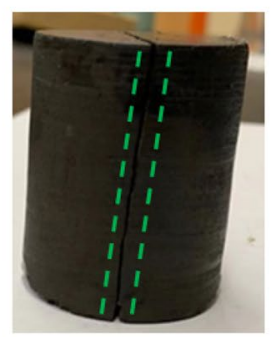

(c)

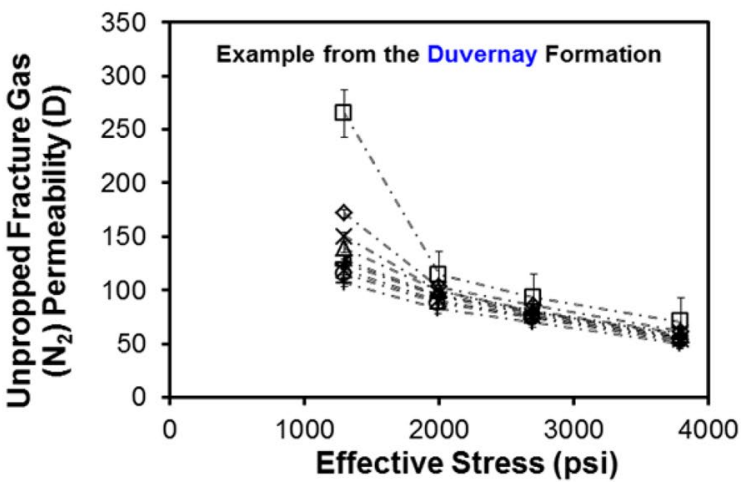

Figure 1. Use of biaxial coreholder to induce fractures in core plugs under stress and measure gas fracture permeability (a); example of core plug sample (Duvernay Formation, western Canada) fractured under differential stress in biaxial coreholder (b); example of unpropped fracture permeability measurements (c). Modified after Ghanizadeh et al. ${ }^{23}$ and Zhang et al. ${ }^{24}$.

The experimental studies of cyclic solvent injection in tight hydrocarbon systems performed to date are extensive, providing much insight into the fundamental mechanisms and controlling factors, but have some limitations (Supplementary Table S1 online). The majority of previous laboratory studies have been performed on core plug samples with permeability values down to the microdarcy/millidarcy range ${ }^{12,13}$ until now, very few laboratory-based studies ${ }^{8,14-17}$ have been conducted on tight hydrocarbon systems with permeability values down to the nanodarcy range (a common permeability range for unconventional hydrocarbon reservoirs). Further, the laboratory methodologies are primarily focused on intact ('unfractured') core plug samples using either the 'flow-through-matrix'12,18,19 or 'flow-around-matrix'1,20,21 schemes, which do not realistically represent the fracture-matrix contact or sequences associated with a typical cyclic solvent injection (HNP) process. While seminal works have been conducted to mimic HNP process on fractured cores ${ }^{7,8}$, the fractures were created outside of the coreholder either fully using saw $^{7}$ or partially using drilling bits ${ }^{8}$ (combined with hydraulic fracturing under stress inside coreholder). These approaches, though more representative, are prone to the creation of stress-induced micro-fractures, particularly in organic-rich shales (the primary target plays for field-scale HNP application). If present, these micro-fractures, the apertures of which may be below the detection limit of CT/ micro-CT scan particularly for larger cores, could act as 'by-pass' flow paths along and in between the primary fractures, causing overlap between different mechanisms. The representative replication of HNP mechanism, de-coupled from flooding mechanism, is a challenge in experimental HNP studies. Multi-fracture geometries, though more representative of subsurface condition, may provide a combination of flooding and HNP mechanisms under laboratory conditions with an elevated effective permeability due to the proximity between saw-cut fractures or hydraulically-induced primary fracture and the artificially-induced micro-fractures. In addition, previous laboratory-based HNP experiments were typically not simulated using a compositional (lab-calibrated) model. More importantly, the experimental durations of previous laboratory techniques are extensively long, even for fractured cores (typically $15-20 \mathrm{~h} \mathrm{per} \mathrm{cycle}^{7,8}$ ). This limitation hinders the experimental throughput, and the capacity for characterizing the HNP mechanisms/controls over diverse experimental conditions in a timely fashion.

In order to represent the core-based HNP process at 'near-fracture' conditions from locally depleted tight oil reservoirs, a new set of experiments are designed herein whereby core-flooding is performed on core plug samples that have been artificially fractured in a process analogous to "in-situ" fracturing. In previous work by Ghanizadeh et al. ${ }^{22,23}$, it was demonstrated that (gas) fracture permeability could be measured on the intact core plug samples after artificial fractures were created in the rock under stress through application of differential stress in a conventional biaxial coreholder (Fig. 1). This method is designed to create the fracture inside the coreholder under stress by gradually increasing the axial load while keeping the radial load constant, until an axial splitting (i.e. fracture) is induced in the core plug (presumably) along the weakest plane (e.g., existing bedding lamination, etc.). While this approach (biaxial rather than shear) does not fully capture the complexity of natural fractures induced under sub-surface conditions, it is expected to mimic the "in-situ" fracturing conditions (i.e. fracturing under stress) better compared to the conventional methods (e.g., Brazilian test) in which the fracture is created artificially outside of the coreholder using uniaxial stress. This approach has enabled the measurement of tight rock unpropped/propped fracture permeability/conductivity ${ }^{23}$, and fracture compressibility ${ }^{24}$ under "in-situ" stress and as a function of effective stress.

In this work, a new workflow is proposed for core-based HNP experiments in fractured core plug samples as follows (Supplementary Fig. S1 online): (1) an intact core plug sample is first fractured under stress through application of differential stress inside the coreholder (no use of saw or drill bit); (2) the fractured core plug is saturated with oil by re-injecting formation oil back into the sample using liquid pump; (3) gas (e.g. $\mathrm{CO}_{2}$, lean gas) is injected into the sample and allowed to soak, to mimic the injection and soaking periods of a field-scale HNP scheme; (4) the injected gas is then re-injected in the upstream end at high pressure, and the effluent is 
measured at the downstream end. This set of experiments is expected to be more representative of 'near-fracture' conditions because (1) gas and liquid flow occurs through an actual "induced" fracture along the core plug sample, and (2) "in-situ" stress, and stress variation regimes during injection, soaking and flow is reproduced.

Core-flooding experiments require careful design in terms of the length of the injection, soaking and production periods, injected fluid volumes and pressures, and frequency of effluent sampling, among other considerations. Core-based simulation, when combined with actual measurements, has proven to be significantly helpful in our previous studies for developing new fluid flow experimental techniques ${ }^{25,26}$ and evaluating the impact of micro-scale heterogeneities on lab-based petrophysical and geomechanical data ${ }^{27}$. One of the novelties of this work is the optimization of the experimental HNP design by simulating the experiments using a compositional numerical simulator, with the core plug as the reservoir, prior to the actual tests. The simulator takes into account the various mechanisms (e.g. multi-phase advection through fracture, diffusion through matrix, oil solvation, etc.) that are expected in a core-based HNP experiment. Simulation of the experiments beforehand "de-risks" the tests, improving the chance of success (i.e. higher recovery). This aspect is beneficial for experimental design, particularly considering the overwhelming number of possible operational combinations (e.g. injection/production pressure/time, soaking time, gas type, etc.) that can be chosen for a given core-based HNP test. Apart from experimental design optimization, compositional numerical simulation is used in this work to history-match each cycle, enabling the fundamental controlling mechanisms to be explored after the experiments are completed. As a continuation of a previous work focused on $\mathrm{CO}_{2} \mathrm{HNP}^{28}$, the current study is the first to couple experimental and modeling approaches for core-based comparison of $\mathrm{CO}_{2}$ and (simplified) lean gas HNP performance in low-permeability fractured reservoirs.

\section{Numerical simulation: prior to experiments}

In order to assist with the experimental design prior to conducting the actual tests, and to select the optimum experimental conditions (leading to highest recovery), numerical simulations were implemented to simulate the expected oil recovery during the first four cycles of $\mathrm{CO}_{2} \mathrm{HNP}$ experiments. Based on previous laboratory fluid analysis results ${ }^{6}$, a 7 -component equation of state (EOS) was developed using tNavigator (version 20.1: https:// rfdyn.com/tnavigator/). The mole fractions of the fluid components in the model were obtained by performing a two-phase flash to represent the dead oil sample used in the experiment. The composition of flashed oil at room conditions $\left(1 \mathrm{~atm}, 25^{\circ} \mathrm{C}\right.$ ) indicates that the majority of components are C5 to C12 (Supplementary Table S2 online). The phase envelope of the (simulated) dead oil is shown in Supplementary Fig. S2 online.

A numerical model was built prior to the $\mathrm{CO}_{2} \mathrm{HNP}$ experiment using the petrophysical properties of the intact $^{29}$ and fractured ${ }^{24}$ twin core plug samples to represent the matrix and fracture system in the simulation (Supplementary Fig. S3 online). This cuboid model was designed to have a similar surface area and pore volume as the actual cylindrical core plug samples used in this study. The model included $20 \times 1 \times 18$ global cells in the $\mathrm{x}, \mathrm{y}$ and $\mathrm{z}$ directions, respectively. The fracture-hosting cells were refined by logarithmic spacing to accurately model the flow towards the surface of an embedded fracture with a width of $\sim 0.003 \mathrm{~cm}$. The simulations were conducted using an effective gas diffusion coefficient $(D)$ of $7 \times 10^{-4} \mathrm{~cm}^{2} / \mathrm{s}$ for the $\mathrm{CO}_{2}$ component only $\mathrm{y}^{30}$. The oil effective diffusion coefficient was set to be an order of magnitude smaller than the gas diffusion coefficient. Additionally, a uniform initial oil saturation $=100 \%$ and matrix porosity $=2.8 \%$ were assumed for the core plug sample. The stress-dependent matrix ${ }^{29}$ and fracture (formation oil) permeability (Supplementary Appendix S2 online), both derived from laboratory analysis, were employed to further constrain the flow simulations.

Nearly 1000 compositional simulation runs were performed to determine an optimal design for the $\mathrm{CO}_{2} \mathrm{HNP}$ experiment. The parameters were selected using manual sensitivity analysis with the objective of optimizing the performance of core-based huff-n-puff process (i.e. higher oil production/recovery over shorter period). The effective diffusion/dispersion coefficients and the fracture aperture were selected as the primary input parameters for optimizing the experimental conditions because they were highly uncertain and the most impactful on oil production/recovery. Matrix permeability was also adjusted slightly but only within the range previously reported for other (Duvernay shale) twin core plug samples with similar porosity and organic/inorganic composition ${ }^{31}$. Two-phase (gas/liquid) relative permeability data, obtained for tight siliceous samples ${ }^{29}$ from the Western Canadian Sedimentary Basin were also among the initial selected parameters to constrain the simulation. However, for near-miscible scenarios (the case herein), its impact was determined to be insignificant based on repeated simulations $\left(\mathrm{CO}_{2}\right)$ using another set of relative permeability curves obtained for other tight formations ${ }^{32}$. The numerical simulations were used to determine Minimum Miscibility Pressure (MMP) between $\mathrm{CO}_{2}$ and the "in-situ" (dead) oil, as well as the duration of gas injection, injection pressure, soaking and production periods. As for the simplified lean gas HNP tests, similar experimental conditions (i.e. injection time/pressure; soaking time; and production time) were applied without performing the "prior to experiment" simulations, in order to obtain a direct comparison between the two HNP EOR schemes $\left(\mathrm{CO}_{2}\right.$ vs. simplified lean gas). In addition to experimental design, the simulation models used for experimental design were also used to history match the experimental oil recovery data after the actual experiments with $\mathrm{CO}_{2}$ and simplified lean gas were completed.

While ideal, there are considerable numerical complexities/challenges associated with using small grid blocks in the available commercial reservoir simulators for miscible/near-miscible scenarios where diffusion/dispersion is included. Using a fully implicit scheme to include the effective diffusion/dispersion coefficient as an input, precautions were taken when selecting the grid blocks to (1) ensure the gridding is small enough to effectively capture the associated physics and avoid numerical dispersion as much as possible, and, (2) avoid simulation failure due to very small grid blocks. The small explicit fracture in the numerical simulation model was represented by grid blocks as small as $0.003 \mathrm{~cm}$ that can be optimally simulated (i.e. without any failure) by the available commercial reservoir simulators. The near-fracture grids were further refined to around $0.04 \mathrm{~cm}$ with larger grids up to a maximum of $\sim 0.18 \mathrm{~cm}$ in the regions far away from the fracture. 


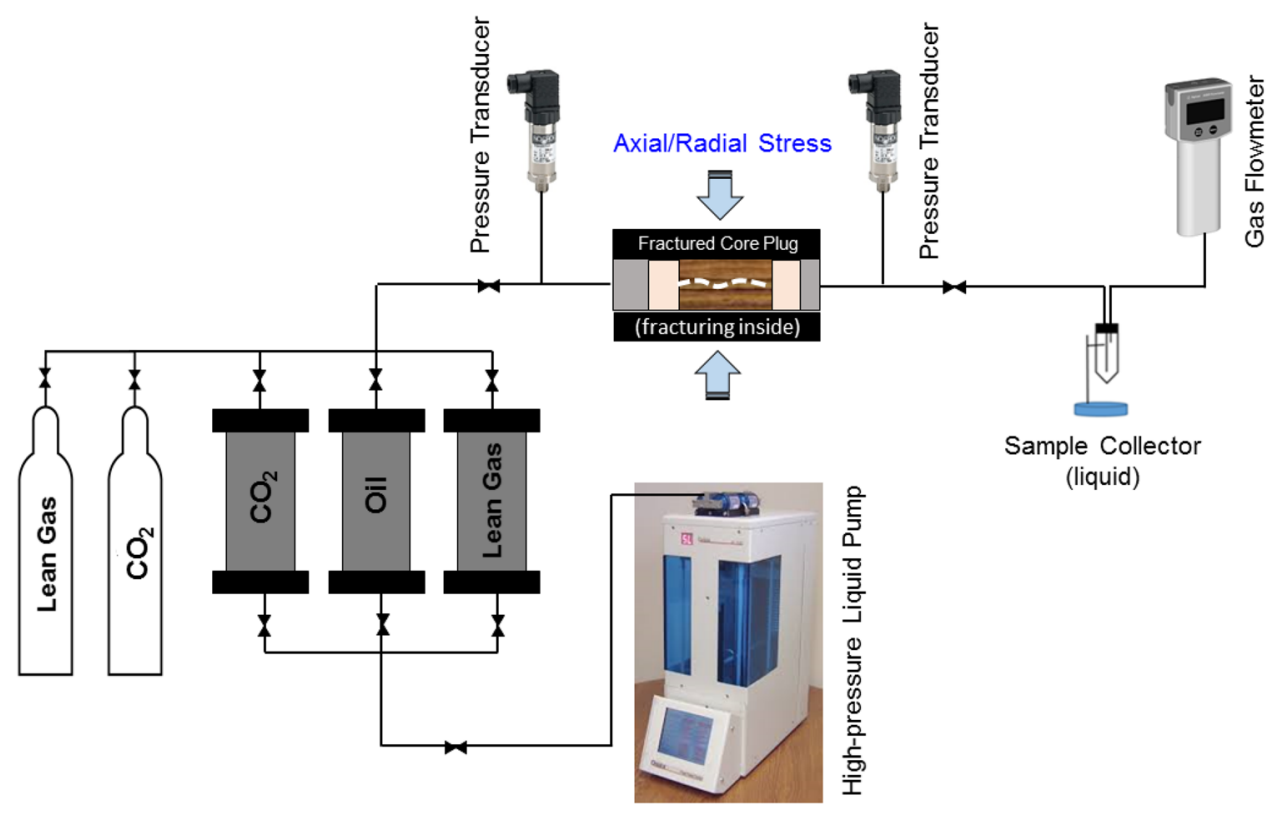

Figure 2. Schematic of the experimental setup designed and built in-house for the cyclic solvent (gas) injection (HNP) experiments.

\section{Experiments}

Experimental setup. The experimental setup for the cyclic solvent (gas) injection includes a high-pressure fluid injection pump, gas $\left(\mathrm{CO}_{2}\right.$, lean/rich gas) cylinder, fluid transfer cylinders, high-pressure coreholder, pressure transducers, produced oil sample collector, gas flowmeter, gas sampling cylinders and various valves to control the flow in and out of the coreholder (Fig. 2). The coreholder is capable of applying a confining pressure up to 10,000 psi to mimic in-situ stress conditions. The confining pressure can be applied in radial and axial directions, independently (i.e. biaxial coreholder). Using the high-pressure (5000 psi) pump, oil and liquefied $\mathrm{CO}_{2}$ stored in the transfer cylinders can be injected into the coreholder at either constant flow rate or constant pressure conditions to perform liquid permeability and HNP experiments. The injection pressure and production pressure between two ends of the coreholder are monitored and recorded by two separate pressure transducers with an accuracy of $\pm 0.025 \%$ of full scale $(0-6000 \mathrm{psi})$. The produced liquid and gas samples are separated in the oil sample collector that consists of a measurement tube with graduated volume $(0.01 \mathrm{cc})$. Cumulative oil production is recorded using the sample collector while the gas production is measured using a gas flowmeter $(0-1,000 \mathrm{ml} / \mathrm{min}$ flow rate range). The produced gas samples are collected in a gas sampling cylinder $(0-500$ psi pressure range) during HNP experiments for compositional analysis. In this experimental setup, the downstream dead volume was comprised of the volume within a capillary tube $(0.55-0.8 \mathrm{cc})$ and the dead volume $(\sim 0.20 \mathrm{cc})$ associated with a needle valve (technically inevitable).

Experimental workflow and procedure. The key steps/experiments for core-based HNP, reproduced from Song et al. ${ }^{28}$, were as follows:

1. The liquid permeability device used for steady-state liquid flow tests was calibrated using previouslydesigned in-house permeability standards (micro-capillaries embedded into impermeable acrylic plugs, references within Song et al. ${ }^{28}$ ). To pass the calibration, the measured permeability values should be within $\pm 15 \%$ of the calculated permeability value.

2. A core plug sample with a cemented lamination occurring its entire length was selected (see "Rock sample preparation: fracturing under stress").

3. Helium porosity was measured on the core plug sample (using the helium pycnometry technique combined with calipered dimensions).

4. The core plug sample is assembled into the core-holder and estimated "in-situ" stress is applied, followed by a leak test at about 500 psi higher that the highest working pressure for HNP tests.

5. A fracture was created along the length of the cemented lamination artificially inside of the coreholder by keeping the radial stress constant while increasing the axial stress stepwise-this approach is generally expected to result fracture creation under stress which is more similar to the subsurface conditions, compared to creating fractures outside the coreholder, as discussed previously ${ }^{22,23}$.

6. Unpropped fracture permeability and compressibility with gas $\left(\mathrm{N}_{2}, \mathrm{CH}_{4}\right)$ was measured under loading (i.e. stepwise increase of effective stress; representative of primary depletion) and unloading (i.e. stepwise decrease of effective stress; representative of injection) paths using the steady-state gas flow technique. The gas permeability values were measured after each incremental increase in axial/radial stress conditions 
and repeated within 12-h time intervals under similar experimental conditions until a constant value (within experimental error range) was achieved - the axial/radial stress should be increased (during loading) or decreased (during unloading) only after constant permeability values are reached (as a result of 'stress creep'). Details of unpropped/propped fracture permeability/conductivity ${ }^{23}$ and unpropped fracture compressibility ${ }^{24}$ evaluations are provided elsewhere.

7. The fractured core plug sample was saturated with formation (dead) oil through application of a constant oil pressure of 1500 psi for 5 days-the fractured core plug sample was evacuated for $48 \mathrm{~h}$ prior to oil saturation to remove the air in the matrix and fracture.

8. The oil was thoroughly removed from the dead volumes and the fracture after oil saturation and before the gas injection tests to minimize the error on the original oil-in-place (OOIP) calculations.

9. The core plug sample was removed from the coreholder and the mass was measured to allow the calculation of oil saturation and OOIP using helium porosity data obtained previously (step 3).

10. The unpropped fracture permeability (and compressibility) was measured with liquid (formation oil) under loading and unloading paths using the steady-state liquid flow technique. The liquid permeability values were measured after each incremental increase in axial/radial stress conditions and repeated within 12-h time intervals under similar experimental conditions until a constant value (within experimental error range) was reached. To examine the impact of flow rate on fractured oil permeability, oil was injected into the fractured core plug sample at different flow rates $(0.5-1.5 \mathrm{cc} / \mathrm{min})$ under varying effective stress conditions (500-3800 psi). Darcy's law was used to determine the liquid (oil) permeability of the fractured core plug under each flow rate and effective stress conditions.

11. $\mathrm{CO}_{2}$ or simplified lean gas were injected into the core plug sample at a constant pressure, followed by a soaking period $(1 \mathrm{~h})$ for each cycle of the HNP process-during $\mathrm{CO}_{2} \mathrm{HNP}$ cycles, liquefied $\mathrm{CO}_{2}$ was injected into coreholder from the inlet end with a constant pressure of 1340 psi for $1 \mathrm{~h}$ until reaching the miscible condition, while during the lean gas HNP cycles, simplified lean gas was injected into the coreholder from the inlet end with a constant pressure of 1280 psi for $1 \mathrm{~h}$. Prior to $\mathrm{CO}_{2} \mathrm{HNP}$ experiment, the minimum miscibility pressure (MMP) between the Duvernay (dead) oil and $\mathrm{CO}_{2}$ was estimated from the slim tube simulation and found to be about 1028 psi. This MMP was also consistent with the values predicted from correlations. Using the slim tube simulation results, a constant $\mathrm{CO}_{2}$ injection pressure of higher than 1028 psi (i.e. 1340 psi) was employed in the $\mathrm{CO}_{2} \mathrm{HNP}$ experiments to avoid immiscible conditions. Similar experimental conditions were applied during the lean gas HNP process for better comparison of the recovery performance.

12. The gas (e.g. $\mathrm{CO}_{2}$ or lean gas)/oil mixture was produced by decreasing downstream pressure to atmospheric pressure for a specific period of time ( $0-4 \mathrm{~h}$, depending on the cycle) until the point where recovery factor was lower than $1-2 \%$ of OOIP.

13. Produced gas and oil were sub-sampled after selected steps for compositional analysis.

14. Steps 11-13 were repeated for multiple cycles, measuring oil and gas production for each step, and oil/ gas composition after selected steps-in total, six and four cycles of $\mathrm{CO}_{2}$ and lean gas $\mathrm{HNP}$ tests were performed herein, respectively.

During the $\mathrm{CO}_{2} \mathrm{HNP}$ process, initially, four cycles of HNP experiments were conducted under the experimental conditions described herein. However, in order to evaluate the impact of varying experimental conditions on the oil recovery, a cycle (\#5) with shorter injection time $(0.5 \mathrm{~h})$, no soaking and a shorter production time $(1 \mathrm{~h})$ was employed. Thereafter, keeping the injection and production conditions identical to those of cycle \#5, an additional cycle (\#6) was conducted with $1 \mathrm{~h}$ of soaking to further evaluate the effect of soaking time on recovery performance. During the simplified lean gas HNP process (cycle \#1-4), similar experimental conditions were applied as the first four cycles of $\mathrm{CO}_{2} \mathrm{HNP}$ process described above (e.g. $1 \mathrm{~h}$ of gas injection, $1 \mathrm{~h}$ of soaking and $4 \mathrm{~h}$ of production) for direct comparison of the EOR performance using the two different gases.

\section{Results}

$\mathrm{CO}_{2}$ vs. simplified lean gas HNP. Based on the measured oil recovery after each cycle (Fig. 3a), it is evident that the majority of oil recovery (up to 80\%) occurs during the first two cycles either for the $\mathrm{CO}_{2}$ or lean gas HNP (4 cycles in total). Further, time-dependent pressure data (Figs. 3b, 4) indicate that there is a pressure drop during each soaking period for $\mathrm{CO}_{2} \mathrm{HNP}$ tests, likely due to $\mathrm{CO}_{2}$ dissolution into the formation oil. However, a very minor pressure drop is evident for the lean gas HNP experiment. For cycles \# 1 to \#4 of the $\mathrm{CO}_{2} \mathrm{HNP}$, which were conducted under identical experimental conditions, the rate and magnitude of the observed pressure drop decrease with each cycle. The impact of operational conditions on the performance of core-based HNP (with $\mathrm{CO}_{2}$, as example) is discussed in Supplementary Appendix S3 online.

The observed pressure drops are partly controlled by the effective diffusion/dispersion process (next section), which is a form of dissolution, as proposed before for other gas/liquid diffusion/dispersion models (e.g. Crank $1975^{33}$ ). The substantial pressure drops for $\mathrm{CO}_{2}$ are due to larger $\mathrm{CO}_{2}$ effective diffusion/dispersion coefficient according to the simulation results, that are generally in agreement with the orders of $\mathrm{CO}_{2}$ and lean gas (i.e. $\left.\mathrm{CH}_{4}\right)$ dissolution in typical dead oil samples (2-3 times ${ }^{34}$ higher for $\mathrm{CO}_{2}$ compared to $\left.\mathrm{CH}_{4}\right)$.

There are still considerable experimental challenges associated with the accurate determination of oil recovery during cyclic gas injection in low-porosity rocks. The experimental error and uncertainty in recovered oil volumes and recovery factors are discussed in detail in Supplementary Appendix S4.

History matching: post experiments. Several parameters were modified in the base simulation models to match the measured oil recovery profiles. History matching was conducted manually to achieve the 

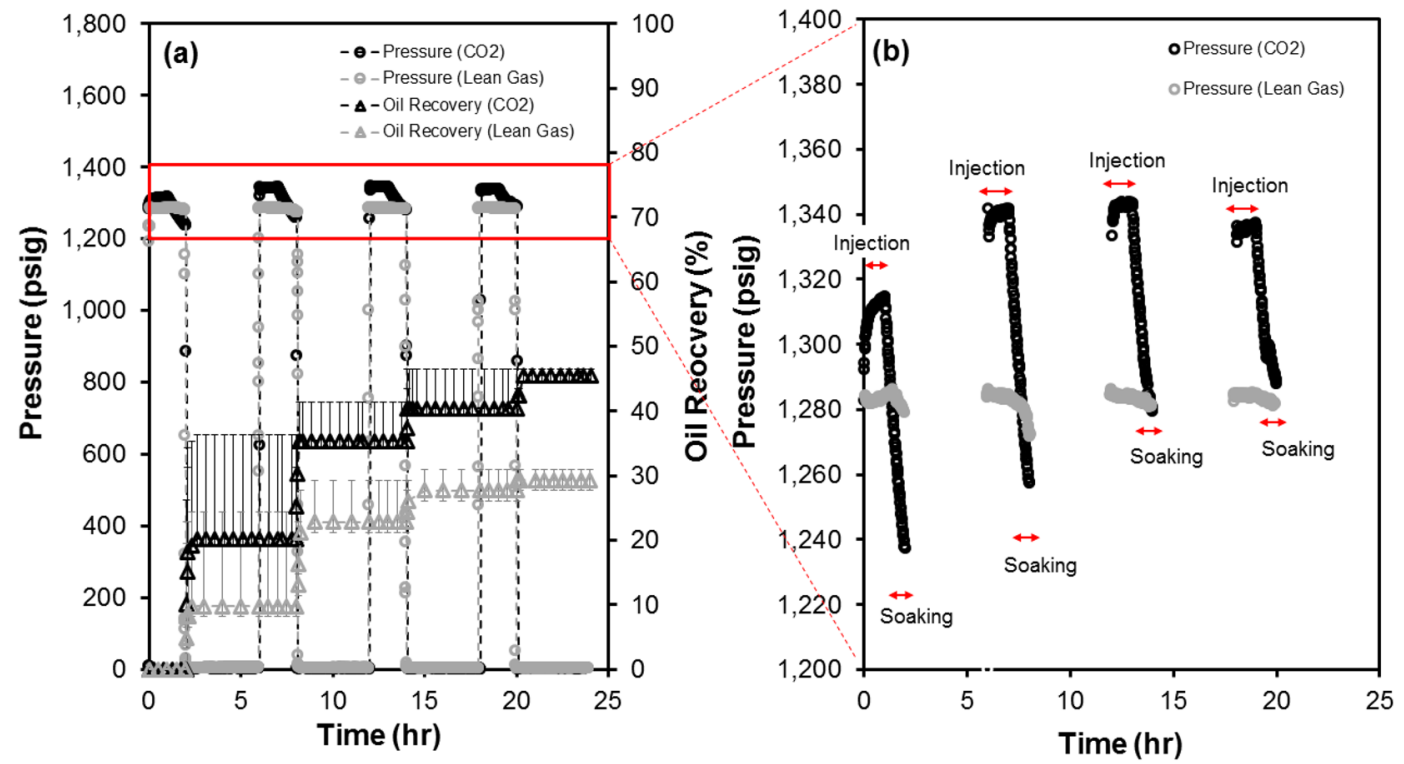

Figure 3. (a,b) Oil recovery and injection/production pressures (4 cycles) as a function of (elapsed) time for the $\mathrm{CO}_{2}$ and lean gas $\mathrm{HNP}$ cycles performed on twin core plug samples (a). $\mathrm{CO}_{2}$ data are adopted from Song et al. ${ }^{28}$ while lean gas data are generated in this work. Pressure decay profiles for $\mathrm{CO}_{2}$ and lean gas in an enlarged view (b).

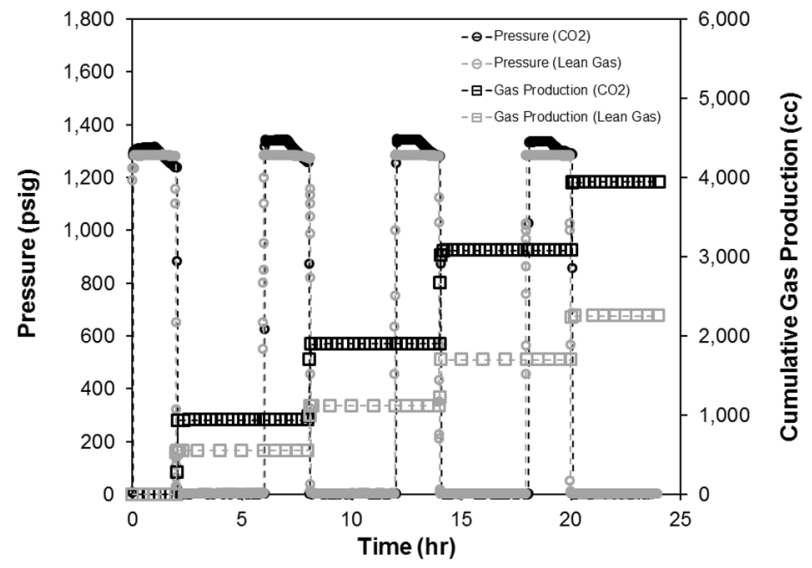

Figure 4. Cumulative gas production and injection/production pressures as a function of (elapsed) time for the $\mathrm{CO}_{2}$ and lean gas $\mathrm{HNP}$ cycles performed on the twin core plug samples (4 cycles). $\mathrm{CO}_{2}$ data are adopted from Song et al. ${ }^{28}$ while lean gas data are generated in this work.

'best-match' because there were numerical challenges to complete the history matching using other assisted approaches (e.g. Adaptive Differential Evolution ${ }^{35}$ and Bayesian Optimization methods ${ }^{36}$ ). The latter observation is attributed to (1) the small grid block thickness (as small as $0.003 \mathrm{~cm}$ ), (2) the complexity of the compositional simulation for near-miscible conditions, (3) large pore volumes and transmissibility differences between the simulation cells (due to the presence of fracture), and (4) most importantly, including effective dispersion/diffusion coefficient as an input parameter for simulations.

The preliminary (manual) history matching results indicate that a reasonable match can be achieved for both $\mathrm{CO}_{2}$ and lean gas HNP processes (Fig. 5) by changing the effective diffusion/dispersion coefficients and increasing the fracture width for both models (Supplementary Table S3 online). For the $\mathrm{CO}_{2}$ injection, it was assumed that $\mathrm{D}_{\text {oil }}=0.1 \mathrm{D}_{\text {gas }}$.

For the $\mathrm{CO}_{2}$ HNP test (Fig. 5), the sharp increase in oil recovery observed during the first cycle can only be matched with the simulator by allowing more $\mathrm{CO}_{2}$ to flow into the system. The sharp increase could be caused by additional mixing of $\mathrm{CO}_{2}$ and the (dead) oil at the injection face of the core. An attempt was made to test this hypothesis with the numerical model by adding an additional set of vertical grid blocks on the injection side of 


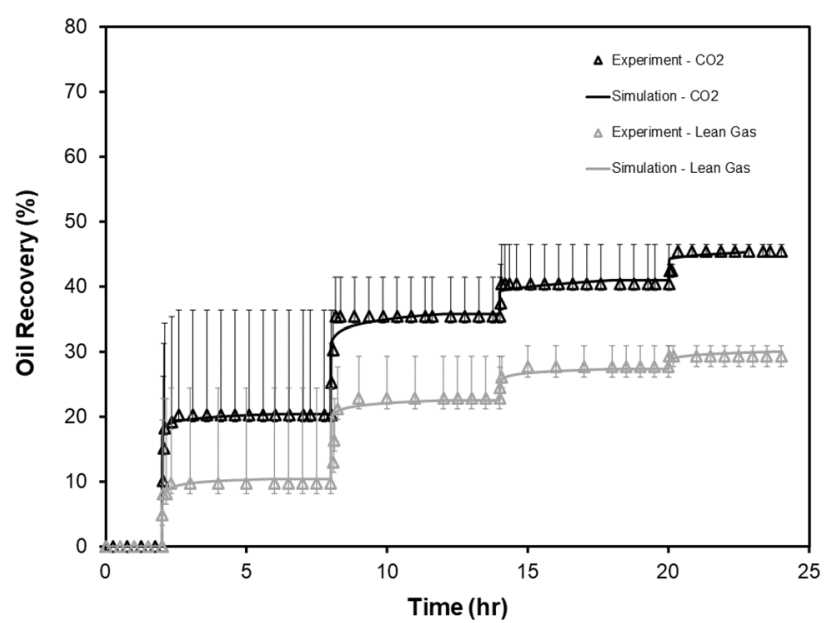

Figure 5. Comparison between experimental and simulated oil recovery as a function of time for the $\mathrm{CO}_{2}$ and lean gas HNP cycles (\#1 to \#4). Note the last two cycles (\#5 and \#6; see Supplementary Appendix S3 online) for $\mathrm{CO}_{2} \mathrm{HNP}$ are not simulated because (1) they were not simulated before the experiments and (2) they did not result in significant additional recovery. $\mathrm{CO}_{2}$ data are adopted from Song et al. ${ }^{28}$ while lean gas data are generated in this work.

the core with large permeability and adjustable pore volumes. However, this approach resulted in instabilities in the compositional simulations. A simpler approach was then tried, which involved increasing the fracture width to permit enough $\mathrm{CO}_{2}$ to flow into the core plug sample.

For the lean gas HNP simulations (Fig. 5), the PVT model was re-constructed from 7 pseudo-components (applied in $\mathrm{CO}_{2} \mathrm{HNP}$ simulation) to 11 pseudo-components where $\mathrm{C}_{1}$ and $\mathrm{C}_{2}$ were considered to be separate components in the simulation. The initial matrix permeability was slightly adjusted to about 30 nd due to the high effective stress (1300 psi; $8.96 \mathrm{MPa}$ ) applied prior to the start of gas injection. Similar to the $\mathrm{CO}_{2} \mathrm{HNP}$ test analysis, the fracture width of the core plug was also increased to allow more gas to flow into the system. For the simulation results, it was found that the slope of the oil recovery curve was sensitive to the effective diffusion/ dispersion coefficients of other components. Therefore, the coefficients of a few other components were also modified for both the $\mathrm{CO}_{2}$ and lean gas injection cases in order to achieve the "best-match" between experiments and simulation model.

The history-matched model indicates that, while the oil recovery for cycle \#1 can be matched reasonably well, there is a slight mismatch between measured and simulated oil recoveries at the beginning of cycles \#2 to \#4 for both $\mathrm{CO}_{2}$ and lean gas. The observed mismatch could be attributed to inherent differences between the nature of experiment and the simulation. In numerical simulation, the produced oil contribution to improved recovery is accounted for as soon as the oil is produced from the core in the simulation. During actual experiments, however, the produced oil may become 'trapped' in the facture or dead volume of the experimental setup instead of flowing out into the sample collector. The remaining oil content, that is associated with an earlier (i.e. previous) cycle, may therefore become part of the produced oil in accompanying subsequent cycle, leading to a sharp and sudden (as a result of abrupt pressure drop) increase in (experimental) recovery profiles at the beginning of cycles \#2 to \#4 for $\mathrm{CO}_{2}$ and lean gas HNP processes.

Note using a 'manual' history matching process (as opposed to an 'assisted'), it was not possible to achieve the "best-match" for all pressure decay profiles for such small system including diffusion/dispersion process. As such, the "best-match" model remains only an approximation. However, while an approximation, the simulated pressure decay profiles (Fig. 6a,b) are capable of predicting higher pressure decay for $\mathrm{CO}_{2}$ than lean gas during the soaking period (in agreement with the experimental data), highlighting the importance of the effective diffusion/dispersion process on cyclic gas injection. Due to the possibility of gas compression in the system as a result of the nature of the experiments (i.e. higher gas volumes injected/produced over larger drawdowns compared to intact cores), the recorded gas volumes were treated with caution, and therefore, the cumulative gas recovery was not considered in the history matching process.

\section{Discussion}

The previous laboratory studies represent a step change in the thinking around experimental evaluation of corebased HNP process through suggesting alternative flow geometries ${ }^{7,20}$, use of large-scale samples/fractures ${ }^{7}$ and combining 'outside-of-coreholder' drilling and advanced core-based hydraulic fracturing under stress inside the coreholder to induce fractures ${ }^{8}$. However, the current work is unique due to (1) the proposed methodology used for creating fractures under stress and (2) its integrated experimental and simulation approach in which a compositional model is calibrated to laboratory data (porosity, matrix/relative permeability, etc.). To our knowledge, this study is the first to fully couple fracturing under stress and EOR approaches with predictive 

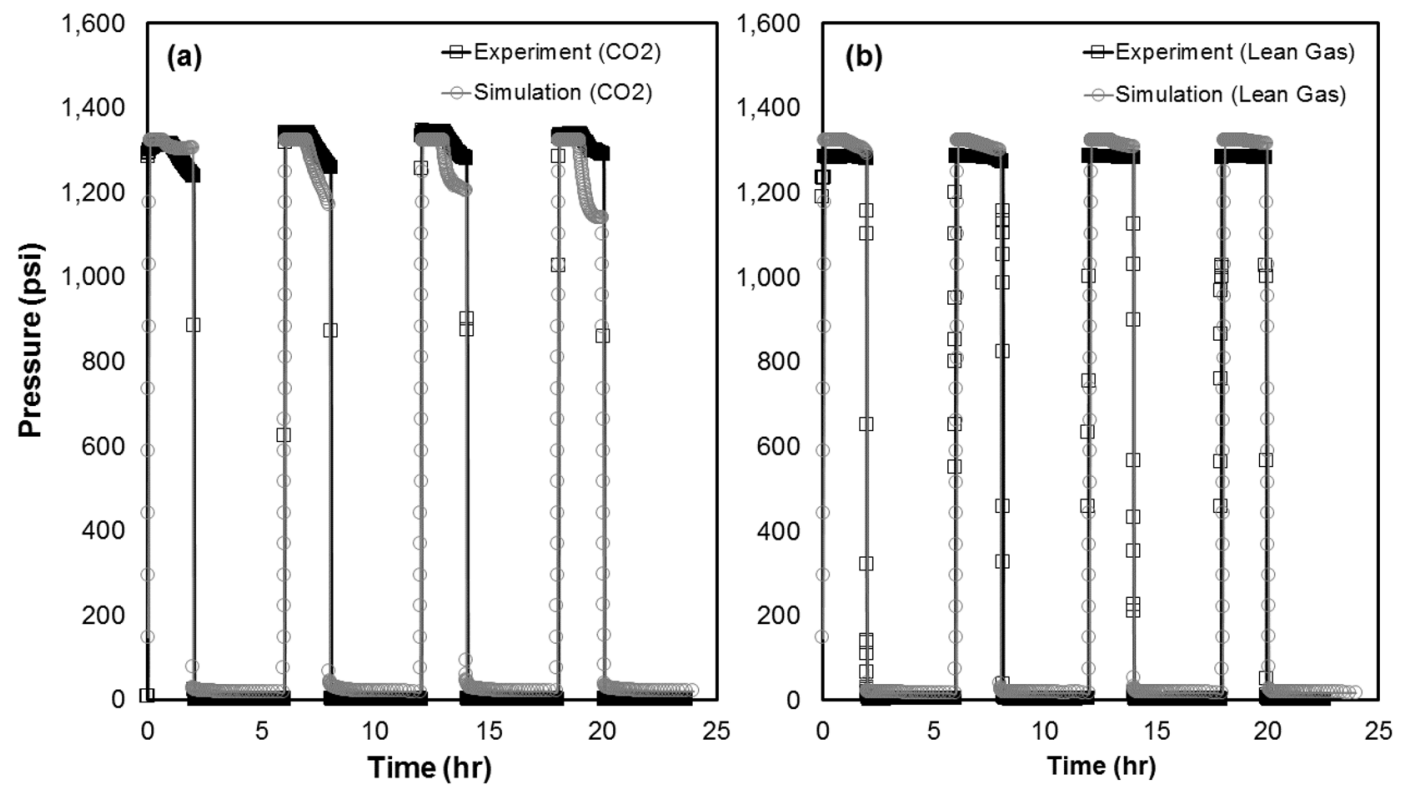

Figure 6. Comparison between experimental and simulated pressure decay profiles for $\mathrm{CO}_{2}(\mathbf{a})$ and lean gas (b).

\begin{tabular}{|c|c|c|c|c|c|c|}
\hline Formation & Porosity (\%) & Permeability (md) & Method & Gas type & Oil recovery (\%) & References \\
\hline \multirow{2}{*}{ Middle Bakken (USA) } & \multirow{2}{*}{$4.4-5.4$} & \multirow{2}{*}{$0.008-0.1$} & \multirow{2}{*}{ "Flow-around" } & Lean gas $^{\mathrm{a}}$ & $>90$ & \multirow{4}{*}{37} \\
\hline & & & & $\mathrm{CO}_{2}$ & $>90$ & \\
\hline \multirow{2}{*}{ Lower Bakken (USA) } & \multirow{2}{*}{3.8} & \multirow{2}{*}{0.005} & \multirow{2}{*}{ "Flow-around" } & Lean gas ${ }^{\mathrm{a}}$ & 27 & \\
\hline & & & & $\mathrm{CO}_{2}$ & 32 & \\
\hline \multirow{2}{*}{ Wolfcamp (USA) } & \multirow{2}{*}{8.5} & \multirow{2}{*}{$0.0003-0.0005$} & \multirow{2}{*}{ "Flow-around" } & $\mathrm{CO}_{2}$ & 65 & \multirow{2}{*}{14} \\
\hline & & & & Lean gas $^{\mathrm{b}}$ & $30-40$ & \\
\hline \multirow{3}{*}{ Middle Bakken (USA) } & \multirow{3}{*}{$4.5-8.1$} & \multirow{3}{*}{$0.002-0.04$} & \multirow{3}{*}{ "Flow-around" } & $\mathrm{CO}_{2}$ & $\sim 95$ & \multirow{3}{*}{38} \\
\hline & & & & Lean gas ${ }^{\mathrm{a}}$ & $\sim 95$ & \\
\hline & & & & 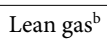 & 92 & \\
\hline
\end{tabular}

Table 1. Comparison of core-based $\mathrm{HNP}$ experiments with $\mathrm{CO}_{2}$ and lean gas in tight oil/gas formations. ${ }^{\text {a }}$ Simplified lean gas $\left(85 \% \mathrm{CH}_{4}+15 \% \mathrm{C}_{2} \mathrm{H}_{6}\right)$ is used in the tests. ${ }^{\mathrm{b}}$ Pure lean gas $\left(100 \% \mathrm{CH}_{4}\right)$ is used in the tests.

fine-tuned simulation models for the purpose of comparing the cyclic gas injection performance of $\mathrm{CO}_{2}$ and lean gas-two primary components of greenhouse gases-in fractured hydrocarbon systems. Compared to previous experimental approaches, the method proposed herein reproduces 'near-fracture' conditions better because (1) fractures are created under stress along the weakest mechanical plane, (2) the actual sequence associated with a HNP cycle is mimicked (injection, soaking and production), (3) gas and liquid flow occur through an actual induced fracture (analogous to a hydraulic fracture created 'in-situ' during a stimulation treatment), and (4) "insitu" stress, and stress variation regimes during injection, soaking and flow are reproduced. Recovery factors of $45 \%$ and $30 \%$ of OOIP were obtained after four cycles of HNP experiments performed on twin Duvernay Shale core plug samples using $\mathrm{CO}_{2}$ and lean gas, respectively. While there may be discrepancies between laboratoryand field-scale recovery factors due to differences between laboratory and field conditions (e.g. dead vs. live $\mathrm{oil}^{8}$, reservoir heterogeneity, etc.), the observed difference between $\mathrm{CO}_{2}$ and lean gas recovery is in agreement with those reported previously in the literature using "flow-through-matrix" or "flow-around-matrix" scenarios (Table 1). Very importantly, however, in contrast to previous laboratory studies performed on intact/fractured cores (Supplementary Table S1 online), these ultimate recovery factors could be achieved in only $24 \mathrm{~h}$ as a result of 1) employing a fractured core plug (i.e. higher surface area) and 2) optimal simulation-aided experimental design. Our integrated workflow therefore provides the opportunity for repeating multiple cycles over a relatively short period of time on a given core plug sample in the laboratory. This in turn provides significant time/costsavings compared to previous approaches, allowing important results to be turned around much more quickly. Note, using the simulations performed prior to the tests, the experimental time scales were selected with the 
criteria of achieving higher oil production/recovery while shortening the total duration of the injection-soakingproduction cycles (not achieving e.g. complete pressure equilibrium after each cycle, etc.).

Besides improved recovery, one of the advantages of using greenhouse gases (e.g. $\mathrm{CO}_{2}$ and lean gas) as solvents is that a portion of the injected gas could be sequestered/trapped in the reservoir via dissolution in the oil, adsorption on the rock surface, amongst other mechanisms. Optimizing the balance between improved hydrocarbon liquid recovery and underground $\mathrm{CO}_{2}$ storage is among future challenges ahead of unconventional hydrocarbon industry due to suppressed commodity prices and associated environmental concerns. Thanks to its fast throughput, one of the advantages of the 'flow-through-frac' method, proposed herein, is that experimental designs and conditions leading to this optimal balance, which in turn can be used to inform field testing, can be determined quickly. For the $\mathrm{CO}_{2} \mathrm{HNP}$ experiments performed herein, only a minor fraction (about $25 \mathrm{cc}$ ) of $\mathrm{CO}_{2}$ was dissolved in the Duvernay (dead) oil under the prevailing conditions compared to the large amount of injected $\mathrm{CO}_{2}(>5000 \mathrm{cc}$ ). The small dissolution is primarily due to low production pressure (i.e. atmospheric) used in the current experiments, leading to low $\mathrm{CO}_{2}$ solubility. Designs to achieve the optimal balance of improved hydrocarbon recovery and underground greenhouse gas storage will be discussed in future studies.

\section{Samples}

Rock samples. The selected core plugs for this study were twin samples obtained from the same well and depth. These samples (1.5" diameter, $2^{\prime \prime}$ length) were drilled parallel to bedding from a $2 / 3$ slabbed core obtained from a vertical well drilled into low-permeability intervals of the Duvernay Formation (Alberta, western Canada). A comprehensive series of geochemical, petrophysical and geomechanical analyses were previously performed on sample pieces and twin core plug samples obtained from the same well and depth ${ }^{29,39}$, serving as an important reference point for the current study. The analyzed samples have the following geochemical and petrophysical properties based on the sub-samples taken from the vicinity of these two core plugs: total organic carbon (TOC) content: 4.26 wt.\%; clay content: $33.3 \%$; quartz content: $44.7 \%$; carbonate content: $12.4 \%$; helium porosity: 2.1-3.3\%; slip-corrected gas $\left(\mathrm{N}_{2}\right)$ permeability $\left(1.25 \cdot 10^{-4} \mathrm{md} ; 900 \mathrm{psi}\right.$ effective stress). Detailed descriptions of the experimental procedures for the determination of TOC content, mineralogical composition, helium porosity, and slip-corrected gas $\left(\mathrm{N}_{2}\right)$ permeability are provided elsewhere ${ }^{22}$.

The core plug samples used in this study were analyzed under "as-received" conditions. "As-received" in the context of this work means that the sample was tested without any further treatment (e.g. cleaning/drying) in the laboratory after drilling.

Rock sample preparation: fracturing under stress. The representativeness and repeatability of the fracture creation procedure is one of the main challenges associated with experimental HNP studies. The 'quality' of the induced fractures is important for core-based HNP data evaluation and history-matching. The assumption of the cubic geometry, that is the basis of the data evaluation and simulation for fractured cores, can be violated depending on the roughness and orientation of the induced fractures. Larger errors in property estimates are associated with deviated fractures (from the core axis) with rougher surfaces.

In this work, the fractures were created along cemented laminations (bedding planes) of core plugs. Cemented laminations are commonly formed parallel to the bedding planes that are perpendicular to the direction of sedimentation, creating planes of weakness. Unlike creating "smooth" saw-cut surfaces, the creation of fractures along weak planes under stress ensures that the fracture conditions are representative of the subsurface fracturing process and can be considered relatively repeatable.

To increase the representativeness and repeatability of the 'flow-through-frac' technique, preferentially, those core plugs that contain a visible laminations and/or cemented micro-fracture should be drilled from the full core (or 2/3 slabbed core) for the tests (Fig. 7). As an example, for Duv 1-1, a series of CT scans were collected in a commercial laboratory to investigate the presence of laminations and/or pre-existing micro-fractures inside the core plug. A primary micro-fracture was detected along the length of the core plug sample (Figs. 7a-c). This micro-fracture, which extends from top to bottom of the core plug, occurs along a mechanically weak plane which is prone to fracturing under differential stress.

Fluids. The formation (dead) oil sample was collected from an active producing field in the Duvernay Formation (western Canada). The formation oil was fully dewaxed with 0.1 micron filters at $25^{\circ} \mathrm{C}$ in a commercial laboratory prior to experiments. The analyzed oil sample has the following physical properties $\left(25^{\circ} \mathrm{C}, 14.7 \mathrm{psi}\right)$ : density: 0.823; viscosity: $2.043 \mathrm{cP}$; and compressibility: $6.5 \cdot 10^{-6} \mathrm{psi}^{-1}$. The $\mathrm{CO}_{2}$ gas used in the $\mathrm{CO}_{2} \mathrm{HNP}$ experiments was at research grade with a purity of $99.998 \%$, and the simplified compositional lean gas $\left(80 \% \mathrm{CH}_{4}+20 \%\right.$ $\mathrm{C}_{2} \mathrm{H}_{6}$ ) used in the lean gas HNP experiment was prepared by a commercial vendor in Calgary, Alberta, Canada.

The objective in this research was to evaluate the proof-of-concept experiments for cyclic gas injection at 'near-fracture' conditions in locally depleted tight oil reservoirs (i.e. with large drawdowns in near-fracture region) that presumably completed the primary recovery process. As such, dead oil samples (as opposed to live oil) were used for HNP experiments without performing any primary recovery tests prior to the HNP tests. 
a)
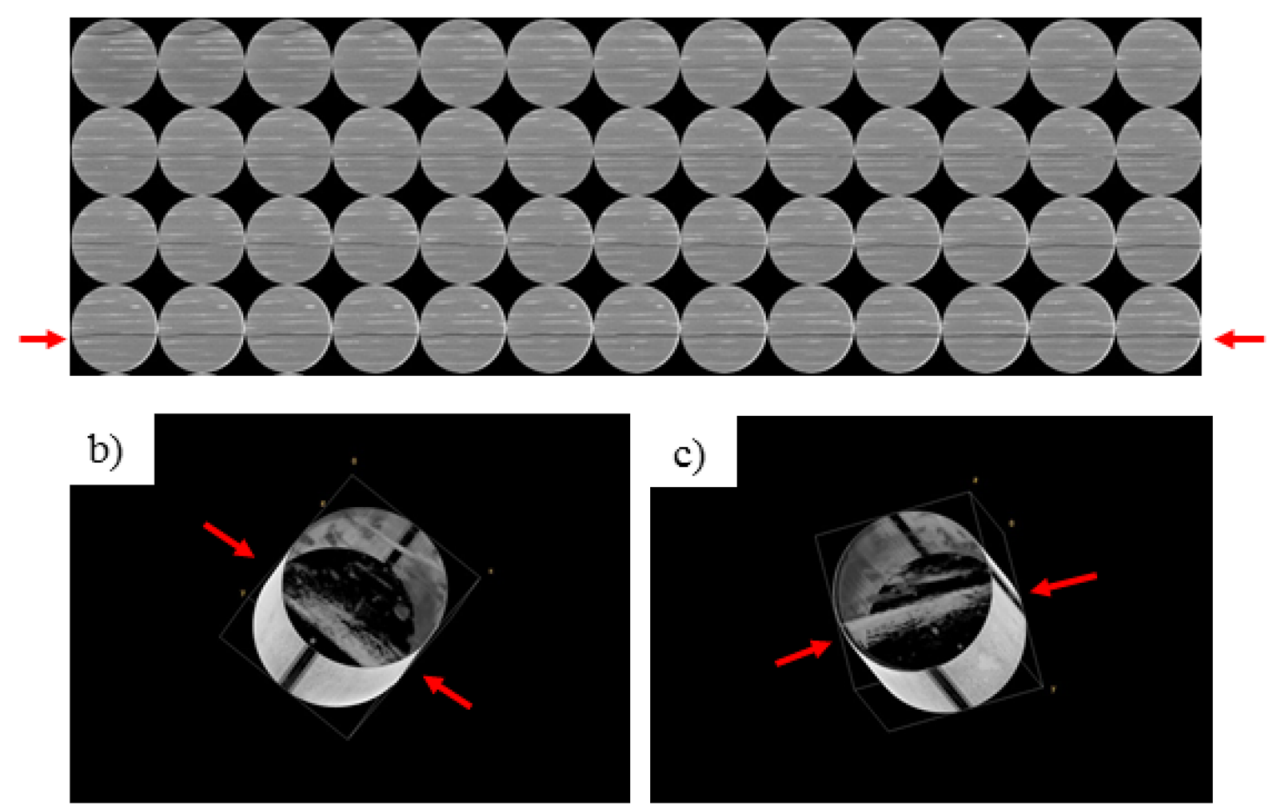

Figure 7. CT scanning images of 2D and processed 3D views of Duv 1-1: (a) 2D, top to bottom; (b) 3D, top to bottom; (c) 3D, bottom to top. A primary cemented lamination that is partly fractured is highlighted with the red arrows $(\mathbf{a}-\mathbf{c})$. There is a secondary fracture close to the edge $(\mathbf{a}, \mathbf{b})$ that is not continuous along the core axis. Drafted using ImageJ (version 1.53a, https://imagej.net/).

Received: 9 November 2020; Accepted: 5 April 2021

Published online: 04 May 2021

\section{References}

1. Hawthorne, S. B. et al. Hydrocarbon mobilization mechanisms using CO2 in an unconventional oil play. Energy Proc. 63 (2014).

2. Kanfar, M. S., Ghaderi, S. M., Clarkson, C. R., Reynolds, M. M. \& Hetherington, C. A Modeling study of EOR potential for CO huff-n-puff in tight oil reservoirs-Example from the Bakken formation. In SPE Unconventional Resources Conference. https://doi. org/10.2118/185026-MS (Society of Petroleum Engineers, 2017).

3. Kanfar, M. S. \& Clarkson, C. R. Factors affecting huff-n-puff efficiency in hydraulically-fractured tight reservoirs. In SPE Unconventional Resources Conference. https://doi.org/10.2118/185062-MS (Society of Petroleum Engineers, 2017).

4. Sharma, S. \& Sheng, J. J. A comparative study of huff-n-puff gas and solvent injection in a shale gas condensate core. J. Nat. Gas Sci. Eng. 38 (2017)

5. Jacobs, T. Shale EOR delivers, so why won't the sector go big? J. Petrol. Technol. 71 (2019).

6. Hamdi, H. et al. Huff-n-puff gas injection performance in shale reservoirs: A case study from Duvernay Shale in Alberta, Canada. In Proceedings of the 6th Unconventional Resources Technology Conference. https://doi.org/10.15530/urtec-2018-2902835 (American Association of Petroleum Geologists, 2018).

7. Thomas, F. B. et al. Experimental measurements of Montney and Duvernay gas-cycling enhanced oil recovery GCEOR. In SPE Canada Unconventional Resources Conference. https://doi.org/10.2118/199994-MS (Society of Petroleum Engineers, 2020).

8. Mahzari, P. et al. Novel laboratory investigation of huff-n-puff gas injection for shale oils under realistic reservoir conditions. Fuel 284 (2021)

9. Li, L., Sheng, J. J., Su, Y. \& Zhan, S. Further investigation of effects of injection pressure and imbibition water on $\mathrm{CO}_{2}$ huff-n-puff performance in liquid-rich shale reservoirs. Energy Fuels 32 (2018).

10. Du, D., Pu, W., Jin, F. \& Liu, R. Experimental study on $\mathrm{EOR}$ by $\mathrm{CO}_{2}$ huff-n-puff and $\mathrm{CO}_{2}$ flooding in tight conglomerate reservoirs with pore scale. Chem. Eng. Res. Des. 156 (2020).

11. Xue-wu, W. et al. Laboratory and field-scale parameter optimization of $\mathrm{CO}_{2}$ huff-n-puff with the staged-fracturing horizontal well in tight oil reservoirs. J. Petrol. Sci. Eng. 186 (2020).

12. $\mathrm{Pu}$, W. et al. Experimental investigation of $\mathrm{CO} 2$ huff-n-puff process for enhancing oil recovery in tight reservoirs. Chem. Eng. Res. Des. 111 (2016).

13. Qian, K. et al. Experimental investigation on microscopic residual oil distribution during $\mathrm{CO}_{2}$ huff-and-puff process in tight oil reservoirs. Energies 11 (2018).

14. Li, L., Sheng, J. J. \& Xu, J. Gas selection for huff-n-puff EOR in shale oil reservoirs based upon experimental and numerical study. In SPE Unconventional Resources Conference. https://doi.org/10.2118/185066-MS (Society of Petroleum Engineers, 2017).

15. Li, L., Zhang, Y. \& Sheng, J. J. Effect of the injection pressure on enhancing oil recovery in shale cores during the $\mathrm{CO}_{2}$ huff-n-puff process when it is above and below the minimum miscibility pressure. Energy Fuels 31 (2017).

16. Yu, Y. \& Sheng, J. J. A comparative experimental study of IOR potential in fractured shale reservoirs by cyclic water and nitrogen gas injection. J. Petrol. Sci. Eng. 149 (2017).

17. Wan, T., Yu, Y. \& Sheng, J. J. Experimental and numerical study of the EOR potential in liquid-rich shales by cyclic gas injection. J. Unconvent. Oil Gas Resour. 12 (2015).

18. Song, C. \& Yang, D. Experimental and numerical evaluation of $\mathrm{CO}_{2}$ huff-n-puff processes in Bakken formation. Fuel 190 (2017).

19. Li, L. et al. A comparative study of $\mathrm{CO}_{2}$ and $\mathrm{N}_{2}$ huff-n-puff EOR performance in shale oil production. J. Petrol. Sci. Eng. 181 (2019). 
20. Hawthorne, S. B. et al. Measured crude oil MMPs with pure and mixed $\mathrm{CO}_{2}$, methane, and ethane, and their relevance to enhanced oil recovery from middle Bakken and Bakken shales. In SPE Unconventional Resources Conference. https://doi.org/10.2118/185072MS (Society of Petroleum Engineers, 2017).

21. Hawthorne, S. B. et al. Hydrocarbon mobilization mechanisms from upper, middle, and lower Bakken reservoir rocks exposed to CO. In SPE Unconventional Resources Conference Canada. https://doi.org/10.2118/167200-MS (Society of Petroleum Engineers, 2013).

22. Ghanizadeh, A., Clarkson, C. R., Aquino, S., Ardakani, O. H. \& Sanei, H. Petrophysical and geomechanical characteristics of Canadian tight oil and liquid-rich gas reservoirs: I. Pore network and permeability characterization. Fuel 153 (2015).

23. Ghanizadeh, A. et al. Unpropped/propped fracture permeability and proppant embedment evaluation: A rigorous core-analysis/ imaging methodology. In Proceedings of the 4th Unconventional Resources Technology Conference. https://doi.org/10.15530/urtec2016-2459818 (American Association of Petroleum Geologists, 2016).

24. Zhang, Z., Clarkson, C. R., Williams-Kovacs, J. D., Yuan, B. \& Ghanizadeh, A. Rigorous estimation of the initial conditions of flowback using a coupled hydraulic-fracture/dynamic-drainage-area leakoff model constrained by laboratory geomechanical data. SPE J. https://doi.org/10.2118/201095-PA (2020).

25. Clarkson, C. R., Nobakht, M., Kaviani, D. \& Kantzas, A. Use of pressure- and rate-transient techniques for analyzing core permeability tests for unconventional reservoirs. In SPE Americas Unconventional Resources Conference. https://doi.org/10.2118/ 154815-MS (Society of Petroleum Engineers, 2012).

26. Clarkson, C. R. \& Qanbari, F. Use of pressure- and rate-transient techniques for analyzing core permeability tests for unconventional reservoirs: Part 2. In SPE Unconventional Resources Conference Canada. https://doi.org/10.2118/167167-MS (Society of Petroleum Engineers, 2013).

27. Solano, N. A., Soroush, M., Clarkson, C. R., Krause, F. F. \& Jensen, J. L. Modeling core-scale permeability anisotropy in highly bioturbated "tight oil" reservoir rocks. Comput. Geosci. 21 (2017).

28. Song, C., Clarkson, C. R., Hamdi, H. \& Ghanizadeh, A. Evaluation of cyclic solvent injection ('huff-n-puff') in artificially-fractured shale core samples: Experiments \& modeling. in Proceedings of the 8th Unconventional Resources Technology Conference. https:// doi.org/10.15530/urtec-2020-3038 (American Association of Petroleum Geologists, 2020).

29. Ghanizadeh, A., Song, C., Clarkson, C. R. \& Younis, A. Relative permeability of tight hydrocarbon systems: An experimental study. Fuel 294119487 (2021).

30. Li, S., Qiao, C., Zhang, C. \& Li, Z. Determination of diffusion coefficients of supercritical CO2 under tight oil reservoir conditions with pressure-decay method. J. CO2 Utiliz. 24 (2018).

31. Ghanizadeh, A. et al. Effects of entrained hydrocarbon and organic-matter components on reservoir quality of organic-rich shales: Implications for «sweet spot» identification and enhanced-oil-recovery applications in the Duvernay formation (Canada). SPE J. 25, 1351-1376 (2020).

32. Shen, Z. \& Sheng, J. J. Experimental and numerical study of permeability reduction caused by asphaltene precipitation and deposition during $\mathrm{CO}_{2}$ huff and puff injection in Eagle Ford shale. Fuel 211, 432-445 (2018).

33. Crank J. The Mathematics of Diffusion. 2nd edn. (Oxford University Press Inc, 1975).

34. DeRuiter, R. A., Nash, L. J. \& Singletary, M. S. Solubility and displacement behavior of a viscous crude with CO2 and hydrocarbon gases. SPE Reserv. Eng. (Society of Petroleum Engineers) 9, 101-106 (1994).

35. Yi, W., Zhou, Y., Gao, L., Li, X. \& Mou, J. An improved adaptive differential evolution algorithm for continuous optimization. Expert Syst. Appl. 44, 1-12 (2016).

36. Hamdi, H., Couckuyt, I., Sousa, M. C. \& Dhaene, T. Gaussian Processes for history-matching: application to an unconventional gas reservoir. Comput. Geosci. 21, 267-287 (2017).

37. Jin, L. et al. Utilization of produced gas for improved oil recovery and reduced emissions from the Bakken formation. In SPE Health, Safety, Security, Environment, \& Social Responsibility Conference-North America. https://doi.org/10.2118/184414-MS (Society of Petroleum Engineers, 2017).

38. Alharthy, N. et al. Enhanced oil recovery in liquid-rich shale reservoirs: Laboratory to field. SPE Reserv. Eval. Eng. 21 (2018).

39. Ghanizadeh, A. et al. Effects of entrained hydrocarbon and organic-matter components on reservoir quality of organic-rich shales: Implications for 'sweet spot' identification and enhanced-oil-recovery applications in the Duvernay formation (Canada). SPE J. $25(2020)$

\section{Acknowledgements}

The authors gratefully thank the sponsors of the Tight Oil Consortium hosted at the Department of Geoscience, University of Calgary. Chris Clarkson would like to acknowledge Ovintiv Inc. (former Encana Corporation) and Shell for support of his Chair position in Unconventional Gas and Light Oil research at the University of Calgary, Department of Geoscience. The authors further thank Natural Sciences and Engineering Research Council of Canada (NSERC) for providing funding for this work through the Collaborative Research and Development (CRDPJ 505339-16) and Alliance (ALLRP 548652-19) grants. Hamidreza Hamdi would like to thank Rock Flow Dynamics Inc. (RFD) for supporting his independent research. An early version of this work, focused on $\mathrm{CO}_{2}$, was prepared for presentation at the Unconventional Resources Technology Conference held in Austin, Texas (20-22 July, 2020) and published as a non-peer-reviewed conference contribution (URTeC 3038). The current manuscript represents a significant update to this pre-cursor work by adding new sets of (1) experiments and (2) simulation runs using lean gas to establish comparisons between $\mathrm{CO}_{2}$ and lean gas huff-n-puff performances. In addition, this version includes new sections elaborating on (a) rock sample preparation and fracturing process, (b) technical challenges associated with experiments and numerical simulations, (c) the sources and degrees of uncertainty, and (d) complimentary 'best-practices' to perform HNP experiments and numerical simulations more effectively for future interested readers. Approval by the Unconventional Resources Technology Conference (URTeC) to publish the material reproduced from URTeC 3038 as a peer-reviewed article is greatly appreciated. The authors thank RFD for the use of tNavigator.

\section{Author contributions}

A.G. is a Research Associate, who was in charge of supervision, conceptualization, investigation and writing/ editing of the manuscript. C.S. is a Research Assistant, who was in charge of conceptualization, investigation, methodology and writing/editing of the manuscript. H.H. is a Research Associate, who was in charge of conceptualization, investigation, methodology and writing/editing of the manuscript. C.R.C. is the principal investigator, who was in charge of funding acquisition, supervision, conceptualization and writing and editing of the manuscript. 


\section{Competing interests}

The authors declare no competing interests.

\section{Additional information}

Supplementary Information The online version contains supplementary material available at https://doi.org/ 10.1038/s41598-021-88247-y.

Correspondence and requests for materials should be addressed to A.G.

Reprints and permissions information is available at www.nature.com/reprints.

Publisher's note Springer Nature remains neutral with regard to jurisdictional claims in published maps and institutional affiliations.

(c) (1) Open Access This article is licensed under a Creative Commons Attribution 4.0 International License, which permits use, sharing, adaptation, distribution and reproduction in any medium or format, as long as you give appropriate credit to the original author(s) and the source, provide a link to the Creative Commons licence, and indicate if changes were made. The images or other third party material in this article are included in the article's Creative Commons licence, unless indicated otherwise in a credit line to the material. If material is not included in the article's Creative Commons licence and your intended use is not permitted by statutory regulation or exceeds the permitted use, you will need to obtain permission directly from the copyright holder. To view a copy of this licence, visit http://creativecommons.org/licenses/by/4.0/.

(C) The Author(s) 2021 